\title{
ARTICLE
}

\section{Quercetin attenuates toosendanin-induced hepatotoxicity through inducing the Nrf2/GCL/GSH antioxidant signaling pathway}

\author{
Yao Jin ${ }^{1}$, Zhen-lin Huang ${ }^{1}$, Li Li ${ }^{2}$, Yang Yang ${ }^{1}$, Chang-hong Wang ${ }^{1}$, Zheng-tao Wang ${ }^{1}$ and Li-li $\mathrm{Ji}^{1}$
}

Toosendanin (TSN) is the main active compound in Toosendan Fructus and Meliae Cortex, two commonly used traditional Chinese medicines. TSN has been reported to induce hepatotoxicity, but its mechanism remains unclear. In this study, we demonstrated the critical role of nuclear factor erythroid 2-related factor 2 (Nrf2) in protecting against TSN-induced hepatotoxicity in mice and human normal liver L-02 cells. In mice, administration of TSN (10 mg/kg)-induced acute liver injury evidenced by increased serum alanine/ aspartate aminotransferase (ALT/AST) and alkaline phosphatase (ALP) activities, and total bilirubin (TBiL) content as well as the histological changes. Furthermore, TSN markedly increased liver reactive oxygen species (ROS) and malondialdehyde (MDA) levels, and decreased liver glutathione (GSH) content and Nrf2 expression. In L-02 cells, TSN $(2 \mu \mathrm{M})$ time-dependently reduced glutamatecysteine ligase $(\mathrm{GCL})$ activity and cellular expression of the catalytic/modify subunit of GCL (GCLC/GCLM). Moreover, TSN reduced cellular GSH content and the increased ROS formation, and time-dependently decreased Nrf2 expression and increased the expression of the Nrf2 inhibitor protein kelch-like ECH-associated protein-1 (Keap1). Pre-administration of quercetin (40, $80 \mathrm{mg} / \mathrm{kg}$ ) effectively inhibited TSN-induced liver oxidative injury and reversed the decreased expression of Nrf2 and GCLC/GCLM in vivo and in vitro. In addition, the quercetin-provided protection against TSN-induced hepatotoxicity was diminished in Nrf2 knock-out mice. In conclusion, TSN decreases cellular GSH content by reducing Nrf2-mediated GCLC/GCLM expression via decreasing Nrf2 expression. Quercetin attenuates TSN-induced hepatotoxicity by inducing the Nrf2/GCL/GSH antioxidant signaling pathway. This study implies that inducing Nrf2 activation may be an effective strategy to prevent TSN-induced hepatotoxicity.

Keywords: quercetin; toosendanin; hepatotoxicity; Nrf2; GSH; GCL; traditional chinese medicine

Acta Pharmacologica Sinica (2019) 40:75-85; https://doi.org/10.1038/s41401-018-0024-8

\section{INTRODUCTION}

Traditional Chinese medicines (TCMs) have been used to treat diseases in China for thousands of years. Currently, they are generally used as alternative and complementary medicines, not only in China but also in the United States, Europe, and Singapore [1-3]. The World Health Organization estimates that $\sim 50-80 \%$ of the population in the world uses herbal medicines. With the wide acceptance of TCMs throughout the world, increasing clinical cases of liver injury induced by herbal medicines have been reported recently [1-4]. Especially in China, it was reported that $\sim 44.2 \%$ cases of liver injury were caused by herbal medicines from 2009 to 2012 [1]. Therefore, we shall pay more attention to TCMinduced hepatotoxicity.

Toosendanin (TSN), a triterpenoid saponin, is the main active compound in Toosendan Fructus (also known as Chuan Lian-Zi) and Meliae Cortex (also known as Ku Lian-Pi) [5, 6]. Toosendan Fructus and Meliae Cortex are traditionally used as digestive tract parasiticides and insecticides in TCMs, and they also have an analgesic effect. However, they have been long documented to be toxic drugs $[5,6]$. Recently, an increasing number of studies have demonstrated the promising anti-tumor efficacy and insecticidal activity of TSN [7-13]. However, TSN was also reported to induce serious hepatotoxicity. TSN caused the death of primary rat hepatocytes by inducing mitochondrial dysfunction and caspase activation [14]. TSN also induced serious liver injury in mice by causing liver glutathione (GSH) depletion, mitochondrial dysfunction, and lipid dysmetabolism [15].

Nuclear factor erythroid 2-related factor 2 (Nrf2), a key oxidative stress-mediated transcription factor, regulates the constitutive and inducible expression of various genes involved in antioxidative responses and detoxification $[16,17]$. Nrf2 has already been a prospective target for new therapeutics in liver disease [17, 18]. Some natural Nrf2 activators have been reported to have great potential in the treatment of liver injury [19]. However, whether Nrf2 is critically involved in preventing TSN-induced liver injury remains unknown. This study aimed to observe the important protective role of Nrf2 against TSN-induced hepatotoxicity.

\footnotetext{
${ }^{1}$ The MOE Key Laboratory for Standardization of Chinese Medicines, Shanghai Key Laboratory of Compound Chinese Medicines and The SATCM Key Laboratory for New

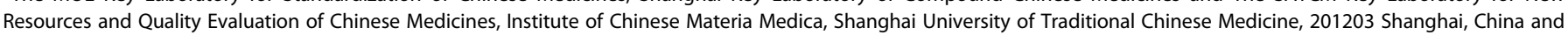
${ }^{2}$ Nanjing Drum Tower Hospital, The Affiliated Hospital of Nanjing University Medical School, 210008 Nanjing, China

Correspondence: Li-li Ji (lichenyue1307@126.com, jilili@shutcm.edu.cn)

These authors contributed equally: Yao Jin, Zhen-lin Huang.
}

Received: 14 December 2017 Accepted: 28 March 2018

Published online: 19 June 2018 
Quercetin is a natural flavonoid with well-known antioxidant capacity [20]. Quercetin has been reported to alleviate liver injury induced by various hepatotoxicants, including pyrrolizidine alkaloids, nickel, lipopolysaccharides/D-galactosamine, triptolide, and carbon tetrachloride [21-26]. Our previous in vitro study showed that quercetin reversed TSN-induced cytotoxicity in human normal liver L-02 cells [27], indicating the potential detoxification of quercetin against TSN-induced liver injury. Moreover, some reports demonstrated that the hepatoprotective effects of quercetin were due to Nrf2 activation [23, 27-29]. In this study, whether quercetin can alleviate TSN-induced liver injury by inducing Nrf2 activation was also studied, which will be helpful to further confirm the critical protective role of Nrf2 in TSN-induced hepatotoxicity.

\section{MATERIALS AND METHODS}

Reagents

Quercetin was purchased from Sigma Chemical Co. (St. Louis, MO, USA). TSN (purity $>98.0 \%$ ) was purchased from Shanghai Tauto Biotech Co., Ltd (Shanghai, China). Kits to detect alanine/aspartate aminotransferase (ALT/AST) and alkaline phosphatase (ALP) activity as well as the total bilirubin (TBil), malondialdehyde (MDA), GSH, and oxidized glutathione (GSSG) contents were all purchased from Nanjing Jiancheng Bioengineering Institute (Nanjing, China). TRIzol, 2'-7'-dichlorodihydrofluorescein diacetate $\left(\mathrm{H}_{2}\right.$ DCFDA) and Lipofectamine 3000 were purchased from Life Technology (Carlsbad, CA, USA). The Cignal Reporter Assay kit for Nrf2/Nrf1 was obtained from Qiagen (Hilden, Germany). The Duan-Glo Luciferase Assay System was purchased from Promega (Madison, WI, USA). Antibodies against ubiquitin and $\beta$-actin were purchased from Cell Signaling Technology (Danvers, MA, USA). Antibodies against Nrf2, catalytic/modify subunit of glutamate-cysteine ligase (GCLC/ GCLM), kelch-like ECH-associated protein-1 (Keap1) and p62 were obtained from Santa Cruz Biotechnology (Santa Cruz, CA, USA). Peroxidase-conjugated goat anti-Rabbit $\lg G(\mathrm{H}+\mathrm{L})$ and anti-Mouse IgG $(\mathrm{H}+\mathrm{L})$ were purchased from Jackson ImmunoResearch (West Grove, PA, USA). The whole-cell protein extraction kit and enhanced chemiluminescence kit were obtained from Millipore (Darmstadt, Germany). The BCA protein assay kit was purchased from ThermoFisher Scientific (Waltham, MA, USA). The PrimeScript Master Mix and SYBR Premix Ex Taq were purchased from Takara (Shiga, Japan). Other reagents, unless indicated, were purchased from Sigma Chemical Co. (St. Louis, MO, USA).

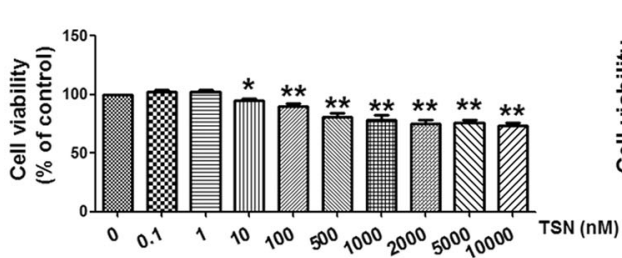

d

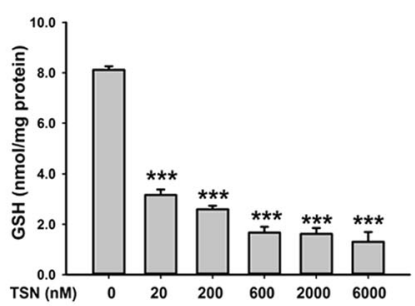

g

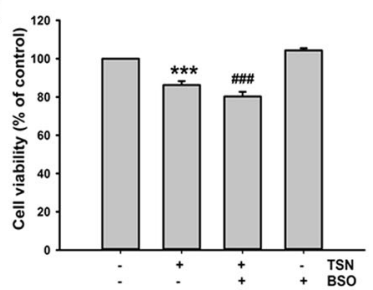

b

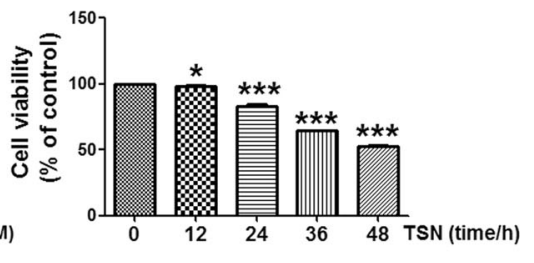

e

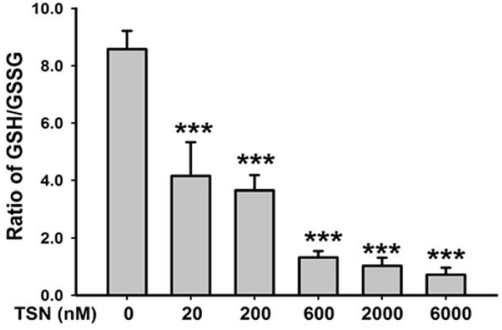

h

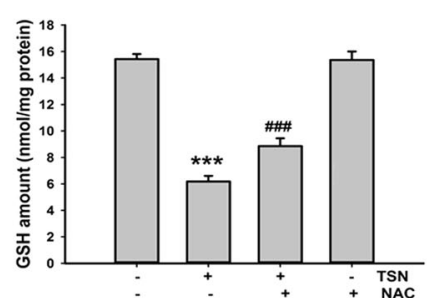

C

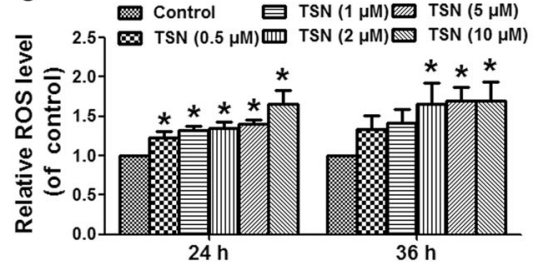

f

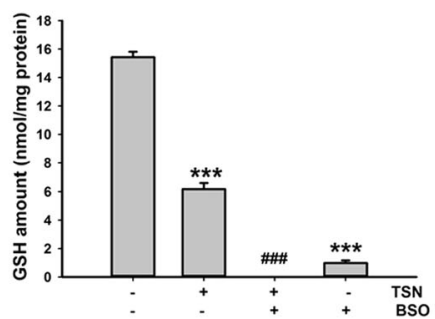

i

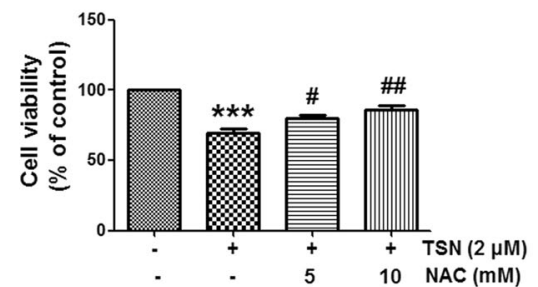

Fig. 1 TSN induces cytotoxicity in hepatocytes. a L-02 cells were incubated with different concentrations of TSN for $48 \mathrm{~h}$, and cell viability was detected. $\mathbf{b}$ L-02 cells were incubated with TSN $(2 \mu \mathrm{M})$ for the indicated time, and cell viability was detected. c L-02 cells were incubated with different concentrations of TSN for $24 \mathrm{~h}$ or $36 \mathrm{~h}$, and cellular ROS formation was detected. d L-02 cells were incubated with different concentrations of TSN for $48 \mathrm{~h}$, and the cellular GSH content was detected. e L-02 cells were incubated with different concentrations of TSN for $48 \mathrm{~h}$, and cellular GSH/GSSG was determined. $\mathrm{f} \mathrm{L}-02$ cells were pre-incubated with BSO $(20 \mu \mathrm{M})$ for $12 \mathrm{~h}$ and were further incubated with TSN $(2 \mu \mathrm{M})$ for $48 \mathrm{~h}$, and then the cellular GSH content was determined. $\mathbf{g}$ L-02 cells were pre-incubated with BSO $(20 \mu \mathrm{M})$ for $12 \mathrm{~h}$ and were further incubated with TSN $(2 \mu \mathrm{M})$ for $48 \mathrm{~h}$, and then the cell viability was determined. $\mathbf{h} \mathrm{L}-02$ cells were pre-incubated with NAC (5 mM) for $2 \mathrm{~h}$ and were further incubated with TSN $(2 \mu \mathrm{M})$ for $48 \mathrm{~h}$, and then the cellular GSH content was determined. i L-02 cells were pre-incubated with NAC $(5,10 \mathrm{mM})$ for $15 \mathrm{~min}$ and were further incubated with TSN $(2 \mu \mathrm{M})$ for $48 \mathrm{~h}$, and then the cell viability was determined. The data are expressed as the mean \pm SEM $(n=3)$. ${ }^{*} P<0.05$, ${ }^{* *} P<0.01,{ }^{* * *} P<0.001$ vs. control; ${ }^{\#} P<0.05$, ${ }^{\# \#} P<0.01$, \#\#\# $P<0.001$ vs. TSN. BSO L-Buthionine-(S, $\left.R\right)$ sulfoximine, NAC $N$-acetyl-cysteine 
a

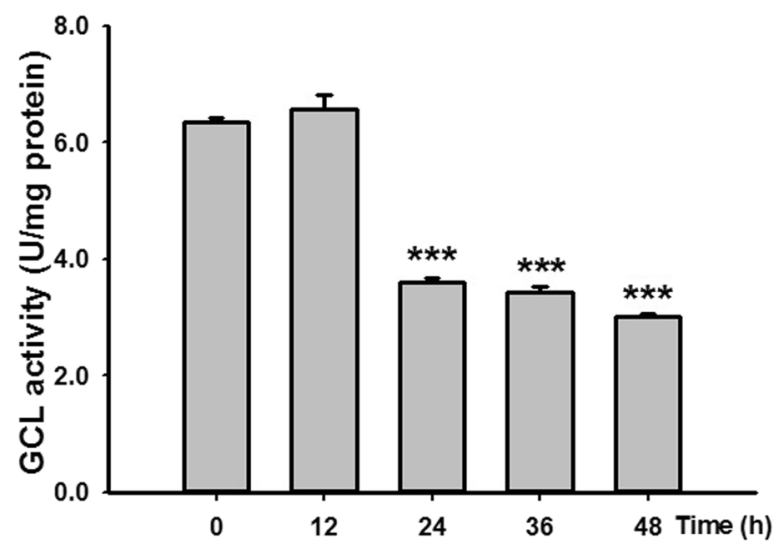

C

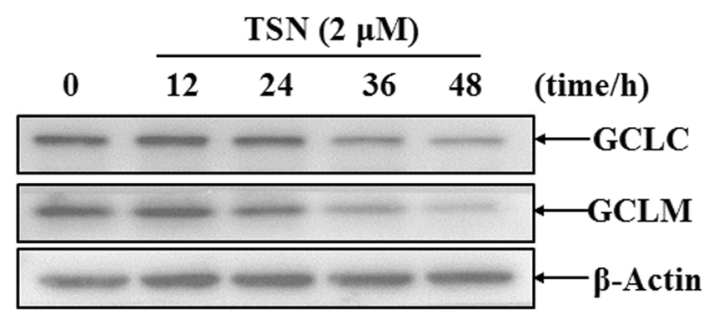

b
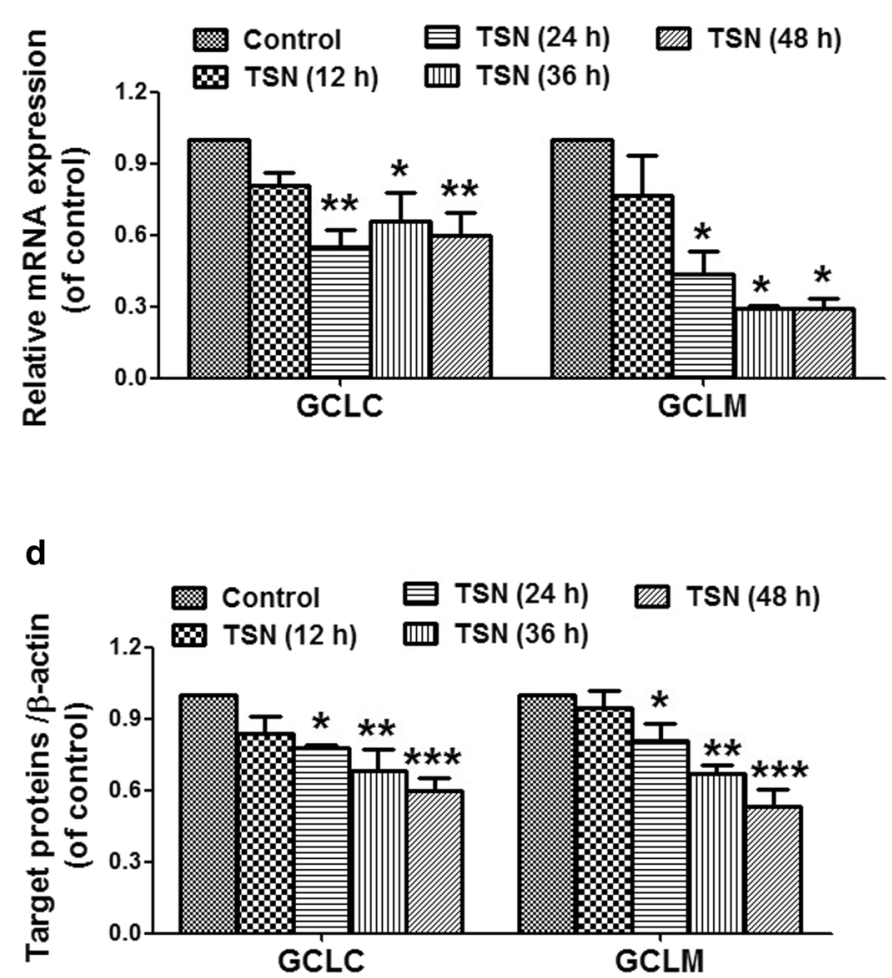

Fig. 2 TSN decreases GCLC/GCM expression and GCL activity in hepatocytes. a L-02 cells were incubated with TSN ( $2 \mu \mathrm{M})$ for the indicated time, and then cellular GCL activity was detected. b L-02 cells were incubated with TSN $(2 \mu \mathrm{M})$ for the indicated time, and cellular mRNA expression of GCLC and GCLM was detected. c L-02 cells were incubated with TSN $(2 \mu \mathrm{M})$ for the indicated time, and cellular protein expression of GCLC and GCLM was detected. The results represent three independent experiments. d Quantitative densitometric analysis of GCLC and GCLM protein. The data are expressed as the mean \pm SEM $(n=3) .{ }^{*} P<0.05,{ }^{* *} P<0.01,{ }^{* * *} P<0.001$ vs. control

Cell culture

The L-02 cell line was purchased from Cell Bank, Type Culture Collection of Chinese Academy of Sciences (Shanghai, China). Cells were cultured in RPMI 1640 supplemented with 10\% [v/v] fetal bovine serum, $2 \mathrm{mM}$ glutamine, $100 \mathrm{U} / \mathrm{mL}$ penicillin and $100 \mathrm{mg} /$ $\mathrm{mL}$ streptomycin.

\section{Cell viability assay}

Cells were incubated with TSN for $48 \mathrm{~h}$ or were incubated with TSN $(2 \mu \mathrm{M})$ for the indicated time. After treatment, cells were incubated with $500 \mu \mathrm{g} / \mathrm{mL}$ 3-(4,5-dimethyl-thiazol-2-yl)-2,5-diphenyltetra-zolium bromide for $4 \mathrm{~h}$. The formed blue formazan was dissolved in $10 \%$ SDS- $5 \%$ iso-butanol- $0.01 \mathrm{M} \mathrm{HCl}$ as described previously [27], and the optical density was measured at 570 with $630 \mathrm{~nm}$ as a reference. Cell viability was normalized as a percentage of the control.

Measurement of cellular and hepatic ROS

Cells were incubated with $\mathrm{H}_{2}$ DCFDA $(20 \mu \mathrm{M})$ and TSN for the indicated time. Cellular reactive oxygen species (ROS) formation and the hepatic ROS level were measured as described in our previously published paper [30]. The results were calculated as units of fluorescence per microgram of protein and were presented as the ratio of the control.

Measurement of the GSH and GSSG contents

The cellular and hepatic GSH contents were determined using commercial kits. The GSH level was expressed as $\mathrm{nmol} / \mathrm{mg}$ protein based on the liver and cellular protein concentrations.
Measurement of GCL activity

Cells were pre-incubated with or without quercetin $(25,50 \mu \mathrm{M})$ for $15 \mathrm{~min}$ and were then incubated with TSN $(2 \mu \mathrm{M})$ for the indicated time. After treatment, the cellular glutamate-cysteine ligase (GCL) activity was assayed as described in our previously published study [31]. GCL activity was calculated based on the protein concentration and was expressed as $\mathrm{U} / \mathrm{mg}$ protein, where 1 unit of $\mathrm{GCL}$ activity was equal to the quantity of the oxidation of $1 \mathrm{mM}$ NADPH per min.

Real-time PCR analysis

Cells were pre-incubated with or without quercetin $(25,50 \mu \mathrm{M})$ for $15 \mathrm{~min}$ and then were incubated with TSN $(2 \mu \mathrm{M})$ for the indicated time. Cellular and hepatic RNA were extracted using TRIzol reagent. cDNA was synthesized, and real-time PCR was conducted. The relative expression of target genes was normalized to that of GAPDH or actin, analyzed by the $2^{-\Delta \Delta C t}$ method and given as a ratio compared with the control. The primer sequences are shown in Supplementary Table 1.

\section{Western blot analysis}

Cells were pre-incubated with or without quercetin $(25,50 \mu \mathrm{M})$ for $15 \mathrm{~min}$ and were then incubated with TSN $(2 \mu \mathrm{M})$ for the indicated time. After treatment, cellular proteins were isolated using wholecell protein extraction kits. Liver samples were homogenized in lysis buffer containing $50 \mathrm{mM}$ Tris (pH 7.5), 1 mM EDTA, $150 \mathrm{mM}$ $\mathrm{NaCl}, 20 \mathrm{mM} \mathrm{NaF}, 0.5 \% \mathrm{NP}-40,10 \%$ glycerol, $1 \mathrm{mM}$ phenylmethylsulfonyl fluoride, $10 \mu \mathrm{g} / \mathrm{mL}$ aprotinin, $10 \mu \mathrm{g} / \mathrm{mL}$ leupeptin, and 10 $\mu \mathrm{g} / \mathrm{mL}$ pepstatin $A$ and were then centrifuged at $3000 \times g$ for $3 \mathrm{~min}$, 


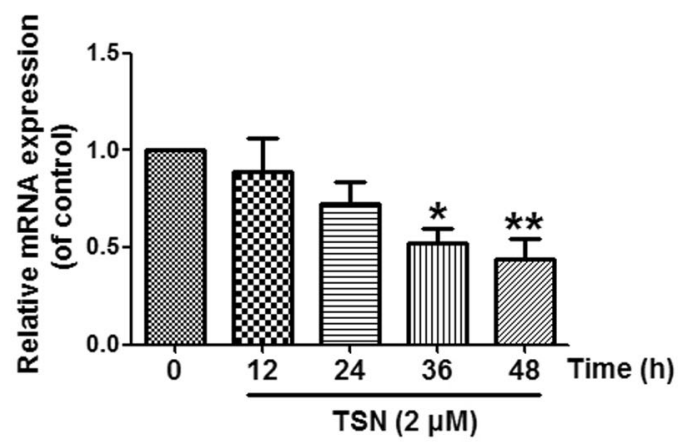

C

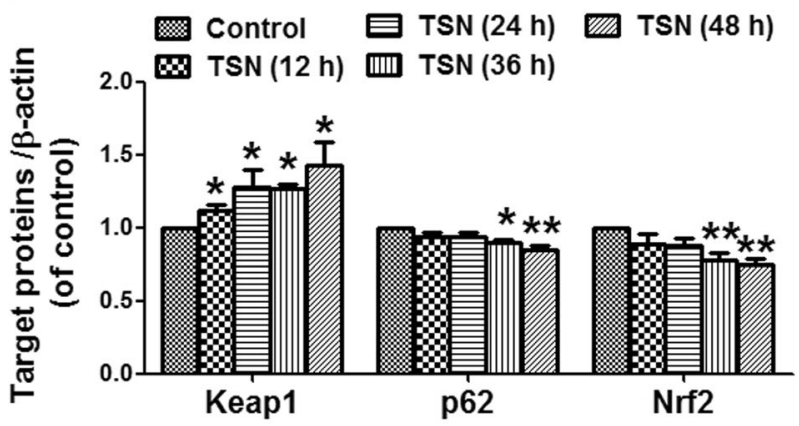

e
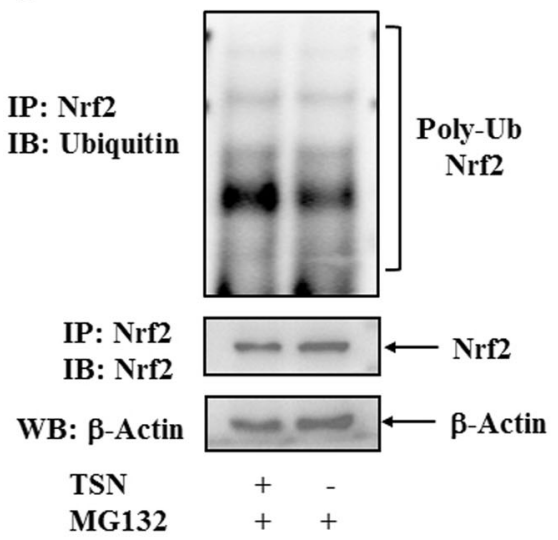

b

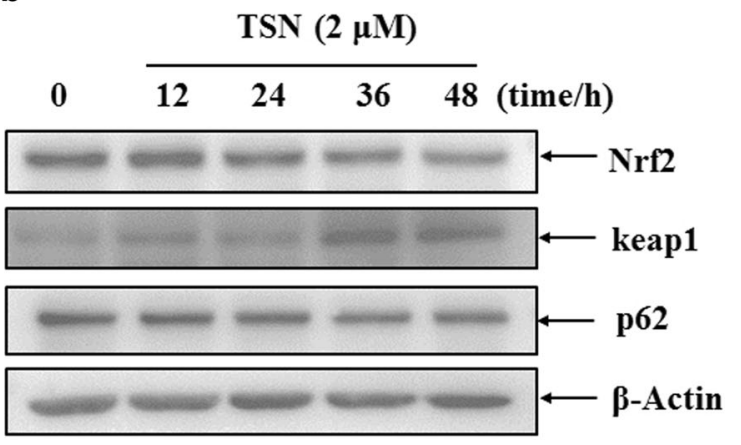

f

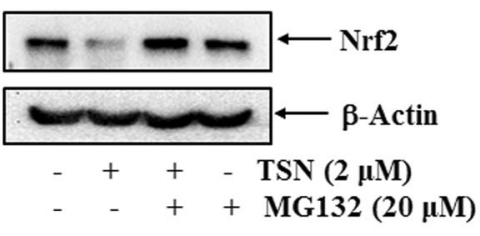

g

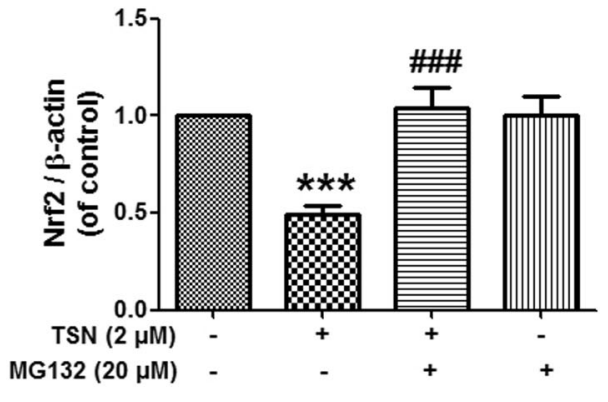

Fig. 3 TSN reduces the expression and activation of Nrf2 in hepatocytes. a L-02 cells were incubated with TSN ( $2 \mu \mathrm{M})$ for the indicated time, and cellular mRNA expression of Nrf2 was detected $(n=3)$. b L-02 cells were incubated with TSN $(2 \mu \mathrm{M})$ for the indicated time, and cellular protein expression of Nrf2, keap1, and p62 was detected. The results represent three to four independent experiments. c Quantitative densitometric analysis of Nrf2, Keap1, and p62 protein $(n=3-4)$. d The Nrf2/1 transcription response element-containing construct was transfected into L-02 cells. After transfection, the cells were incubated with TSN $(2 \mu \mathrm{M})$ for the indicated time. Luciferase activities were measured using a luciferase assay system. Nrf2/1 luciferase activity was expressed as a fold induction of control cells ( $n=3)$. e L-02 cells were pre-treated with MG132 $(20 \mu \mathrm{M})$ for $2 \mathrm{~h}$ and were then incubated with TSN $(2 \mu \mathrm{M})$ for another $36 \mathrm{~h}$. Cell extracts were subjected to immunoprecipitation with anti-Nrf2 antibody, and the conjugates were detected with anti-ubiquitin and anti-Nrf2 antibodies. Each blot represents one of three independent experiments. f L-02 cells were pre-treated with MG132 $(20 \mu \mathrm{M})$ for $2 \mathrm{~h}$ and were then incubated with TSN $(2 \mu \mathrm{M})$ for another $36 \mathrm{~h}$. Cellular Nrf2 expression was detected, and $\beta$-actin was used as a loading control. The results represent three repeated experiments. g Quantitative densitometric analysis of Nrf2 protein $(n=3)$. The data are expressed as the mean \pm SEM. ${ }^{*} P<0.05,{ }^{* *} P<0.01$, ${ }^{* * *} P<0.001$ vs. control; ${ }^{\# \# \#} P<0.001$ vs. TSN

followed by transfer of the supernatant to new tubes. The protein concentrations were measured, and all of the samples in the same experiment were normalized to an equal protein concentration.

The protein samples were separated by SDS-PAGE gel electrophoresis, transferred to a PVDF membrane and incubated with the appropriate combination of primary and secondary antibodies. Proteins were visualized using a chemiluminescent kit. The gray densities of the protein bands were normalized using the $\beta$-actin density, and the results were further normalized to the control values.

Nrf2/Nrf1 luciferase reporter assay

The Nrf2/Nrf1 luciferase reporter assay was performed as described previously using commercial kits. Briefly, L-02 cells were transfected with a Nrf2/1 transcription response elementcontaining construct using Lipofectamine 3000 . After $24 \mathrm{~h}$ of 
a

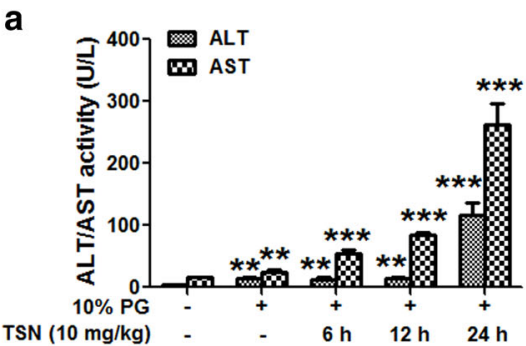

b

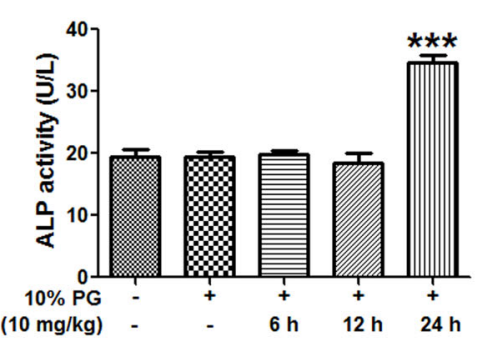

C

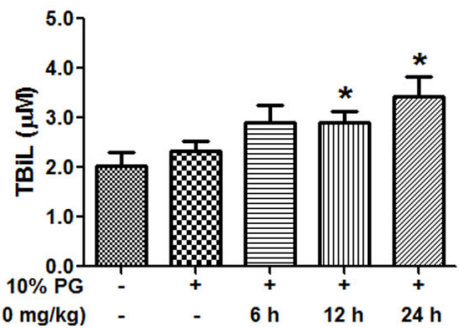

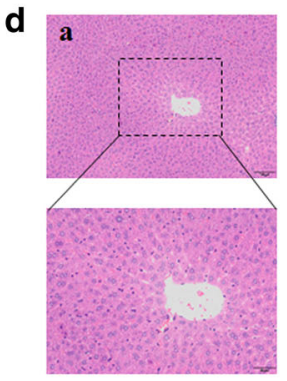
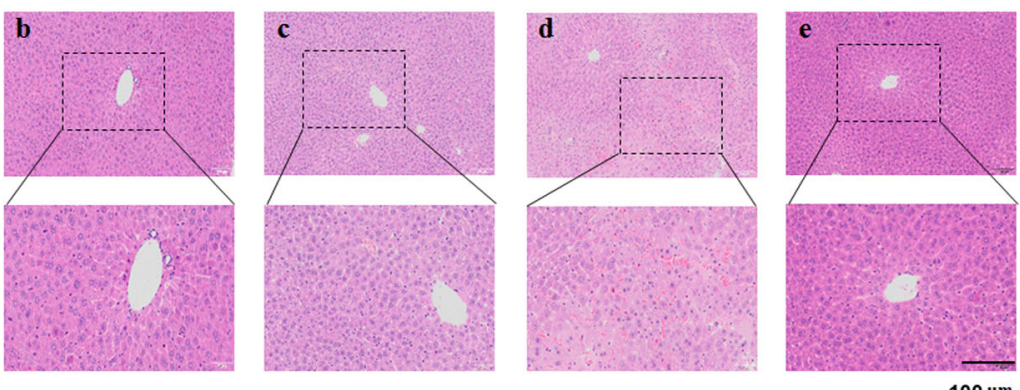

$100 \mu \mathrm{m}$

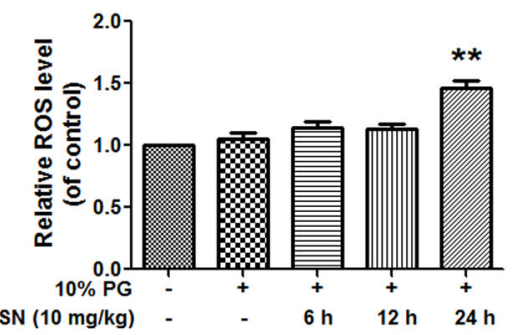

f

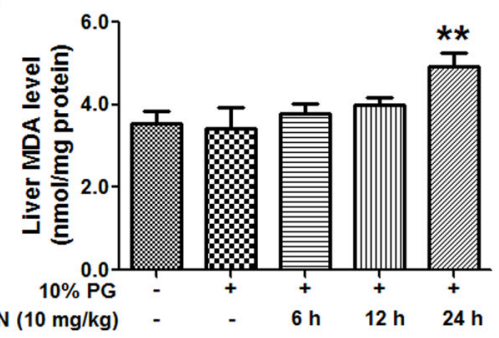

9

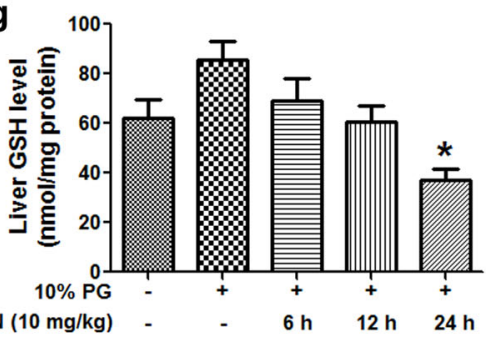

Fig. 4 TSN induces acute liver injury in mice. C57BL/6 mice were treated with TSN $(10 \mathrm{mg} / \mathrm{kg})$ for the indicated time. a Serum ALT and AST activities. b Serum ALP activity. c Serum TBil amount. $\mathbf{d}$ Histological evaluation of liver injury induced by TSN. Typical images were chosen from each experimental group (original magnification $\times 100$, upper images; partial enlarged pictures, $\times 200$, a. control; b. TSN $6 \mathrm{~h}$; c. TSN $12 \mathrm{~h}$; $d$. TSN $24 \mathrm{~h}$; e. 10\% PG). e Liver ROS level. $\mathbf{f}$ Liver MDA content. g Liver GSH amount. The data are expressed as the mean \pm SEM ( $n=6-9)$. * $P<0.05$, ${ }^{* *} P<0.01,{ }^{* * *} P<0.001$ vs. control. PG propylene glycol. Scale bar: $100 \mu \mathrm{m}$

transfection, the cells were pre-treated with or without quercetin for $15 \mathrm{~min}$ and were then incubated with TSN for the additional indicated time. Luciferase activities were measured using the Duan-Glo Luciferase Assay System, and the constitutively expressed Renilla luciferase was used as an internal control.

\section{Immunoprecipitation assay}

To identify polyubiquitinated Nrf2, cells were pre-incubated with the proteasome-specific inhibitor MG132 $(20 \mu \mathrm{M})$ for $2 \mathrm{~h}$ and were then incubated with TSN $(2 \mu \mathrm{M})$ for another $36 \mathrm{~h}$. Cells were lysed in RIPA lysis buffer and the protein concentration was detected, and then, equal amounts of protein were subjected to immunoprecipitation with the anti-Nrf2 antibody as described in kits. The immunoprecipitate was separated via SDS-PAGE, and the conjugates were detected using anti-ubiquitin and anti-Nrf2 antibodies. As a control for the expression of Nrf2 protein, Western blot analysis was also performed using an anti-actin antibody.

\section{Experimental animals}

Specific pathogen-free male C57BL/6 mice (16-20 g body weight) were purchased from Shanghai Laboratory Animal Center of Chinese Academy of Science (Shanghai, China). Nrf2 knock-out $\left(\mathrm{Nrf2}^{-1-}\right)$ C57BL/6 mice were generated by SiDanSai Biotechnology, Inc. (Shanghai, China), using transcription activator-like effector nucleus (TALEN) technology. A pair of TALEN constructs for Nrf2 knock-out were cloned into the mammalian expression vector pCMV-TALEN, and capped, polyA-tailed mRNA for injection was produced using the Ambion mMessage mMachine kits. C57BL/6 knock-out mice were produced by microinjecting TALEN mRNAs into fertilized eggs. The knock-out allele was sequence validated to have two missing base pairs (GA, 346-347 of the ORF), causing a frameshift and an early stop codon. DNA isolated from tail biopsies was used for genotyping. Western blotting was conducted to confirm the deletion of the Nrf2 protein in Nrf2 knock-out mice (Supplementary Figure 1).

Animals were supplied with a standard laboratory diet and water ad libitum at a temperature of $22 \pm 1{ }^{\circ} \mathrm{C}$ with a 12-h lightdark cycle (6:00-18:00) and $65 \pm 5 \%$ humidity. All animals received humane care in compliance with the institutional animal care guidelines approved by the Experimental Animal Ethical Committee, Shanghai University of Traditional Chinese Medicine.

\section{Animal treatments}

To detect the hepatotoxicity induced by TSN, C57BL/6 male mice were randomly divided into 5 groups: (1) normal control $(n=6)$, (2) vehicle control $(n=6),(3)$ TSN $(6 \mathrm{~h})(n=9),(4) \mathrm{TSN}(12 \mathrm{~h})(n=$ 9), and (5) TSN ( $24 \mathrm{~h})(n=9)$. TSN was dissolved in $10 \%$ propylene glycol and was administered (intraperitoneal injection, i.p.) into mice once at a dose of $10 \mathrm{mg} / \mathrm{kg}$. Mice in the vehicle control group were administered $10 \%$ propylene glycol (i.p.). Mice were killed at different indicated time after TSN injection, and plasma and liver tissue were collected. 
a

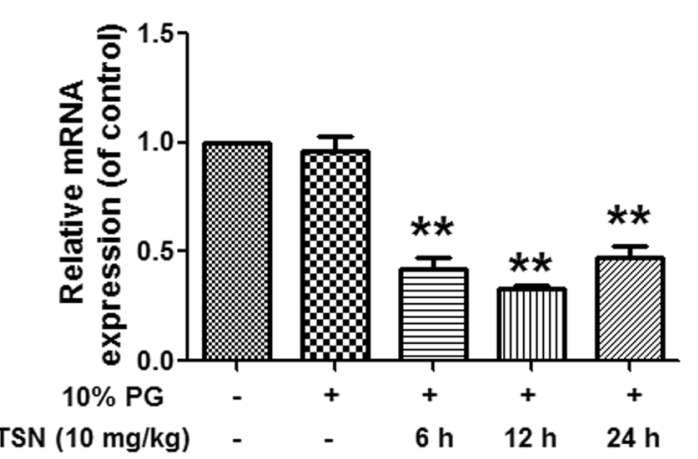

C

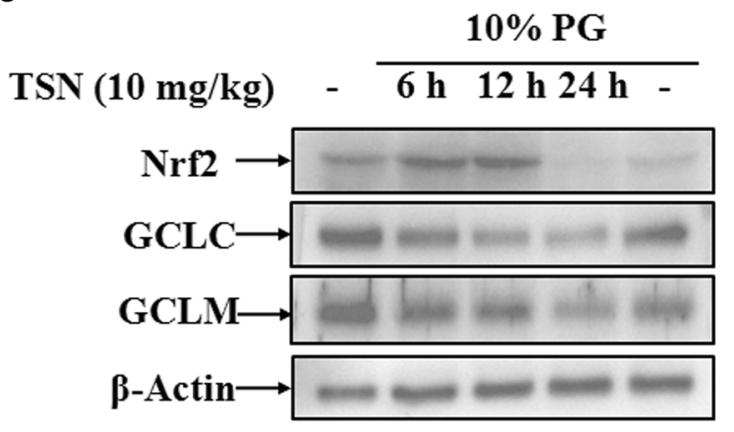

b

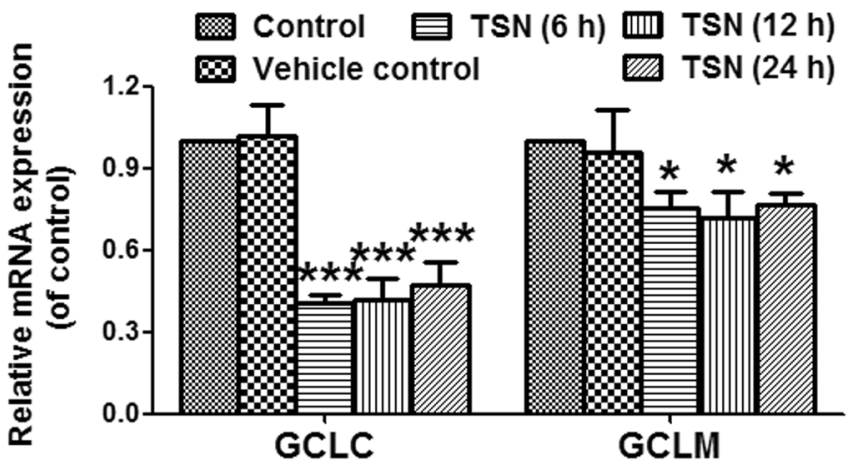

d

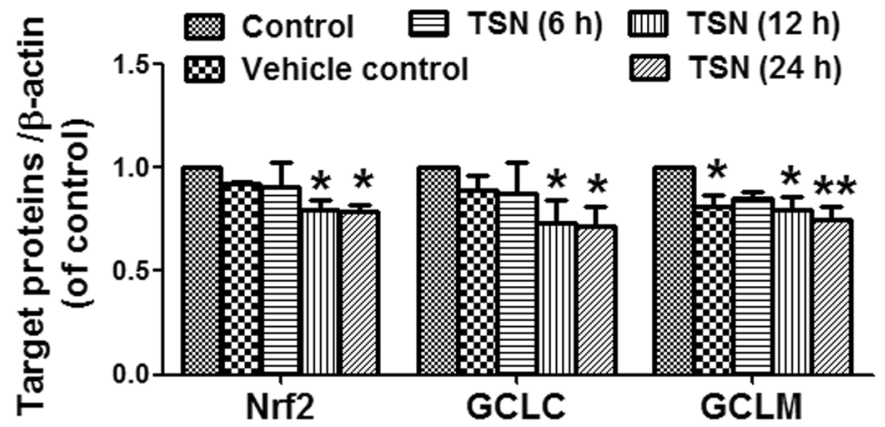

Fig. 5 TSN reduces hepatic expression of Nrf2 and its downstream GCLC/GCLM in mice. C57BL/6 mice were treated with TSN (10 mg/kg) for the indicated time. a Hepatic mRNA expression of Nrf2 $(n=6)$. b Hepatic mRNA expression of GCLC and GCLM $(n=3-4)$. c Hepatic protein expression of Nrf2, GCLC, and GCLM. The results represent three to four repeated experiments. d Quantitative densitometric analysis of Nrf2, GCLC, and GCLM $(n=3-4)$. The data are expressed as the mean \pm SEM. ${ }^{*} P<0.05,{ }^{* *} P<0.01,{ }^{* * *} P<0.001$ vs. control. PG propylene glycol

To detect the protection of quercetin against TSN-induced liver injury, forty-eight C57BL/6 male mice were randomly divided into six groups: (1) normal control $(n=8)$, (2) vehicle control $(n=8),(3)$ TSN $(n=8),(4) \mathrm{TSN}+$ quercetin $(40 \mathrm{mg} / \mathrm{kg})(n=8),(5) \mathrm{TSN}+$ quercetin $(80 \mathrm{mg} / \mathrm{kg})(n=8)$, and (6) quercetin $(80 \mathrm{mg} / \mathrm{kg})(n=8)$. Mice were pre-administered orally with quercetin (intragastric administration, i. g.) $(40,80 \mathrm{mg} / \mathrm{kg})$ for 7 consecutive days and were administered a single dose of TSN $(10 \mathrm{mg} / \mathrm{kg}$, i.p.) at $1 \mathrm{~h}$ after quercetin administration at the seventh day. Mice were killed at $24 \mathrm{~h}$ after the TSN injection, and plasma and liver tissue were collected.

To determine the critical role of Nrf2 in the quercetin-provided protection against TSN-induced liver injury, $\mathrm{Nrf}^{+/+}$and $\mathrm{Nrf2}^{-/-}$ C57BL/6 male mice were randomly divided into three groups: (1) vehicle control, (2) TSN, and (3) TSN + quercetin. Each group contained six mice. Mice were pre-administered quercetin $(80 \mathrm{mg} /$ $\mathrm{kg}$, i.g.) for seven consecutive days. On the last day, mice were administered TSN (10 mg/kg, i.p.) $1 \mathrm{~h}$ after quercetin administration. Mice were killed at $24 \mathrm{~h}$ after the TSN injection, and plasma and liver tissue samples were collected.

Serum biochemistry analysis

Fresh blood was obtained and kept at room temperature for $1 \mathrm{~h}$. Serum was collected after centrifugation at $850 \times \mathrm{g}$ for $15 \mathrm{~min}$. The serum ALT/AST and ALP activity and TBil content were determined using commercial kits.

Liver histological observation

A piece of the liver was fixed in a $10 \%$ phosphate-buffered salineformalin solution and embedded in paraffin. Samples were sectioned $(5 \mu \mathrm{m})$ and stained with hematoxylin-eosin (H\&E) and were then observed under a microscope (Olympus, Japan).
Measurement of liver lipid peroxidation

MDA, formed as the product of liver lipid peroxidation (LPO) and serving as an index for LPO, was determined as described in the kits. The MDA content is expressed as $\mathrm{nmol} / \mathrm{mg}$ protein based on the liver protein concentration.

Statistical analysis

The data are expressed as the mean \pm standard error of the mean (SEM). The significance of differences between groups was evaluated by one-way ANOVA with the LSD post-hoc test, and $P<0.05$ was deemed to indicate statistically significant differences.

\section{RESULTS}

TSN induces cytotoxicity in hepatocytes in vitro

TSN $(0.01-10 \mu \mathrm{M})$ decreased cell viability in human normal liver L02 cells in a concentration-dependent manner (Fig. 1a). TSN (2 $\mu M)$ also obviously reduced cell viability in L-02 cells in a timedependent manner (Fig. 1b). TSN $(2-10 \mu \mathrm{M})$ increased cellular ROS formation in L-02 cells in a concentration-dependent manner after cells were incubated with TSN for $24 \mathrm{~h}$ or $36 \mathrm{~h}$ (Fig. 1c). The data in Fig. 1d and e showed that TSN decreased the cellular GSH content and GSH/GSSG ratio in L-02 cells. L-Buthionine- $(S, R)$ sulfoximine (BSO), an inhibitor of $G C L$, is a rate-limiting enzyme for cellular GSH biosynthesis [32]. BSO further reduced the TSNinduced decrease in the cellular GSH content and cell viability in L-02 cells (Fig. 1f, g). N-acetyl-cysteine (NAC), a precursor of cellular GSH biosynthesis [33], reversed the decreased cellular GSH content and cell viability induced by TSN in L-02 cells (Fig. 1h, i). 


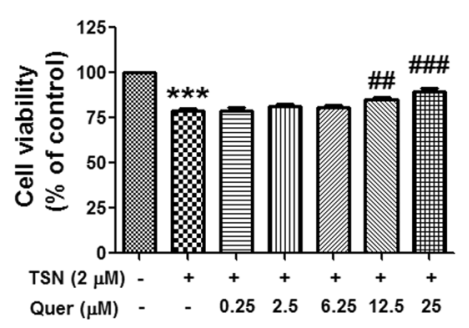

b

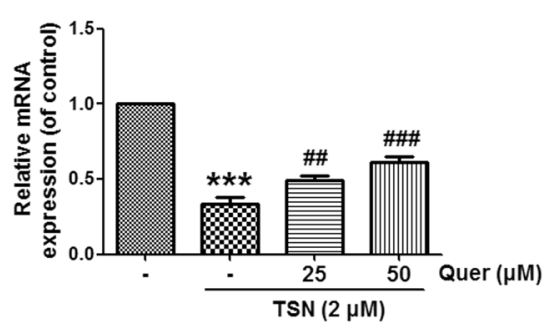

C

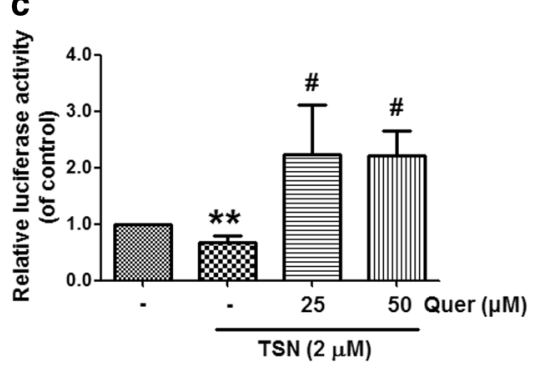

d

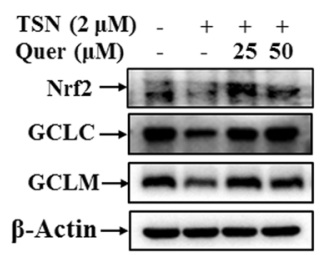

e

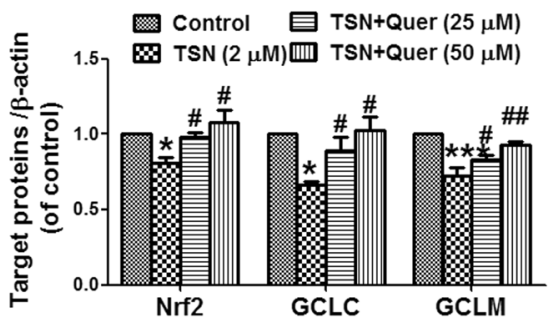

f

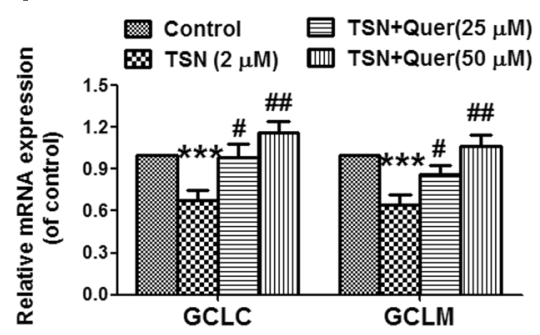

g

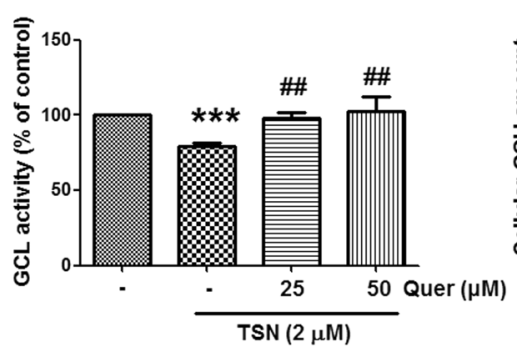

h

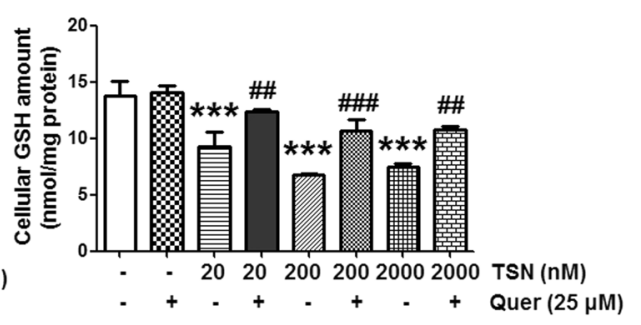

Fig. 6 Quercetin reverses the decreased Nrf2 activation and the increased cytotoxicity induced by TSN in hepatocytes. a L-02 cells were preincubated with different concentrations of quercetin (Quer) for $15 \mathrm{~min}$ and then were further incubated with TSN $(2 \mu \mathrm{M})$ for $48 \mathrm{~h}$. Cell viability was detected $(n=3)$. b L-02 cells were pre-incubated with quercetin $(25,50 \mu \mathrm{M})$ for 15 min and were then further incubated with TSN $(2 \mu \mathrm{M})$ for $48 \mathrm{~h}$. Cellular Nrf2 mRNA expression was detected $(n=3)$. c The Nrf2/1 transcription response element-containing construct was transfected into L-02 cells. After transfection, cells were pre-incubated with quercetin $(25,50 \mu \mathrm{M})$ for 15 min and were then further incubated with TSN $(2 \mu \mathrm{M})$ for another $30 \mathrm{~h}$. Luciferase activities were measured using a luciferase assay system. Nrf2/1 luciferase activity was expressed as a fold induction of control cells $(n=5)$. d L-02 cells were pre-incubated with quercetin $(25,50 \mu \mathrm{M})$ for 15 min and were then further incubated with TSN $(2 \mu \mathrm{M})$ for $48 \mathrm{~h}$. Cellular protein expression of Nrf2, GCLC, and GCLM was detected. The results represent three repeated experiments. e Quantitative densitometric analysis of $\mathrm{Nrf2}, \mathrm{GCLC}$, and GCLM $(n=3)$. $\mathbf{f L}-02$ cells were pre-incubated with quercetin $(25,50 \mu \mathrm{M})$ for $15 \mathrm{~min}$ and were then further incubated with TSN $(2 \mu \mathrm{M})$ for $48 \mathrm{~h}$. Cellular mRNA expression of GCLC and GCLM was detected $(n=5-6)$. g L-02 cells were pre-incubated with quercetin $(25,50 \mu \mathrm{M})$ for 15 min and were then further incubated with TSN $(2 \mu \mathrm{M})$ for $48 \mathrm{~h}$. Cellular GCL activity was detected $(n=4)$. $\mathbf{~ L ~ L - 0 2 ~ c e l l s ~ w e r e ~ p r e - i n c u b a t e d ~ w i t h ~ q u e r c e t i n ~}(25 \mu \mathrm{M})$ for 15 min and were then further incubated with different concentrations of TSN for $48 \mathrm{~h}$. The cellular GSH content was detected $(n=3)$. The data are expressed as the mean \pm SEM. ${ }^{*} P<0.05,{ }^{* *} P<0.01$, ${ }^{* * *} P<0.001$ vs. control; ${ }^{*} P<0.05,{ }^{\# \#} P<0.01,{ }^{\# \# \#} P<0.001$ vs. TSN

TSN decreases GCLC/GCLM expression and GCL activity in hepatocytes

As shown in Fig. 2a, TSN $(2 \mu \mathrm{M})$ decreased $\mathrm{GCL}$ activity after incubation for 24,36 , and $48 \mathrm{~h}$ in L-02 cells. Next, the data in Fig. $2 b$ showed that TSN decreased cellular mRNA expression of GCLC and GCLM, which are catalytic and regulatory subunits of $\mathrm{GCL}$, respectively [34]. Further results showed that TSN decreased cellular protein expression of GCLC and GCLM in L-02 cells after incubation with cells for 24, 36, and $48 \mathrm{~h}$ (Fig. 2c, d).

TSN reduces the expression and activation of Nrf2 in hepatocyte The expression of GCLC and GCLM was reported to be regulated by the key antioxidant transcription factor Nrf2 [34]. Next, we observed the effect of TSN on Nrf2 expression in hepatocytes. The data in Fig. 3a showed that TSN $(2 \mu \mathrm{M})$ reduced cellular mRNA expression of Nrf2 in L-02 cells in a time-dependent manner. TSN $(2 \mu \mathrm{M})$ also reduced cellular protein expression of Nrf2 and p62 and increased Keap1 expression in L-02 cells (Fig. 3b, c). Moreover, the luciferase reporter assay showed that TSN $(2 \mu \mathrm{M})$ reduced
Nrf2/1 transcriptional activation in L-02 cells after incubation for the indicated time (Fig. 3d). Further results showed that TSN (2 $\mu \mathrm{M})$ weakly induced accumulated polyubiquitination of the Nrf2 protein in the presence of the proteasome inhibitor MG132 in L-02 cells (Fig. 3e). In addition, the data in Fig. $3 f$ and $g$ showed that TSN $(2 \mu \mathrm{M})$ decreased Nrf2 protein expression in L-02 cells, but MG132 $(20 \mu \mathrm{M})$ reversed this decrease. All of these results indicate the occurrence of ubiquitin/proteasome-mediated Nrf2 protein degradation induced by TSN.

TSN induces acute liver injury in mice

When mice were treated with TSN $(10 \mathrm{mg} / \mathrm{kg})$ at different time, TSN increased the serum ALT/AST activity in a time-dependent manner (Fig. 4a). TSN increased the serum ALP activity and TBil content when mice were treated with TSN for $24 \mathrm{~h}$ (Fig. 4b, c). TSN also increased the serum TBil content when mice were treated with TSN for $12 \mathrm{~h}$ (Fig. 4c). The results of the liver histological evaluation further demonstrated liver injury induced by TSN. Particularly, in mice treated with TSN for $24 \mathrm{~h}$, serious liver damage 
a

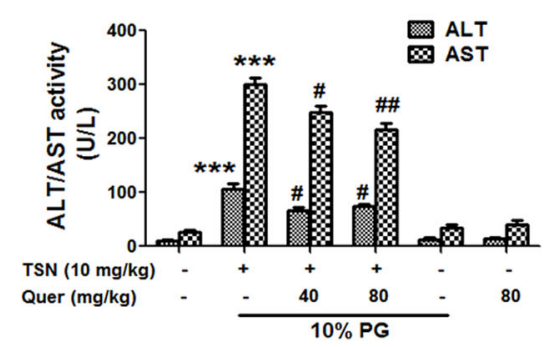

d

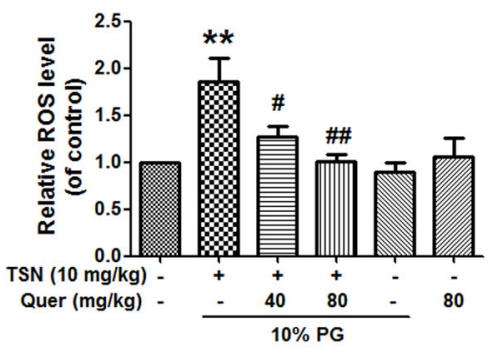

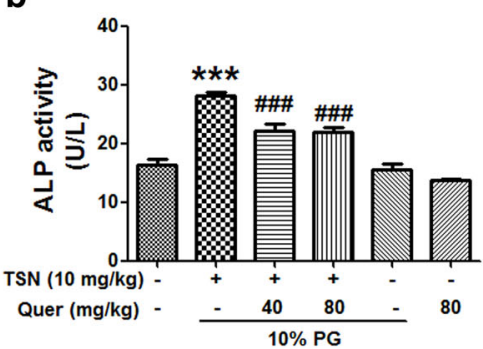

e

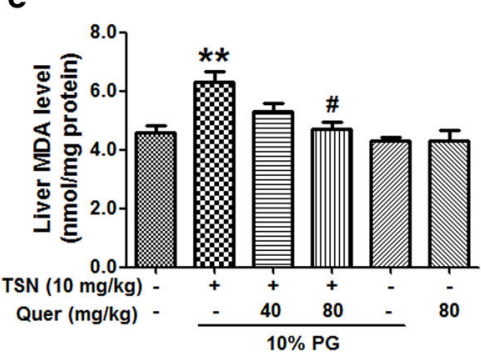

C

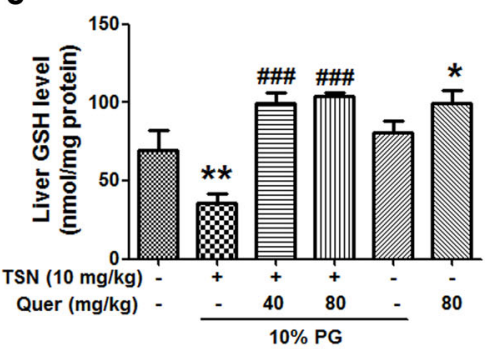

f

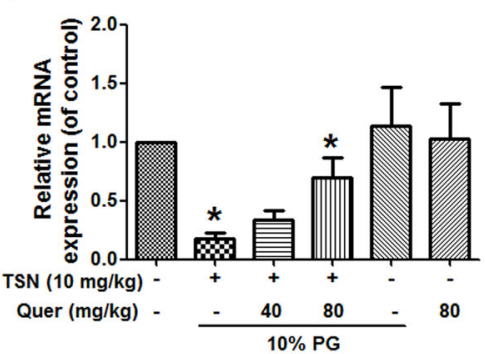

g

i

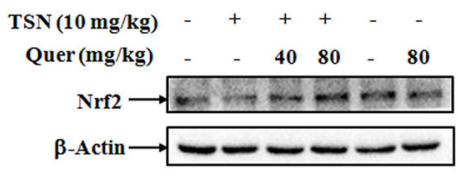

h

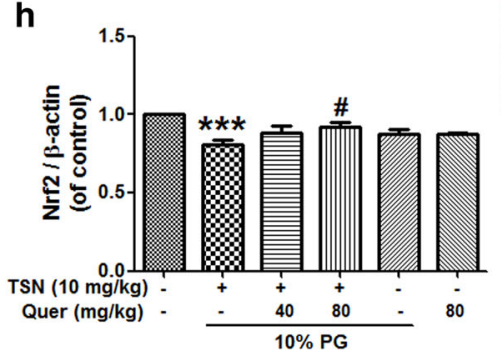

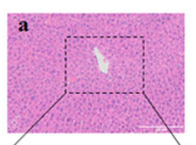
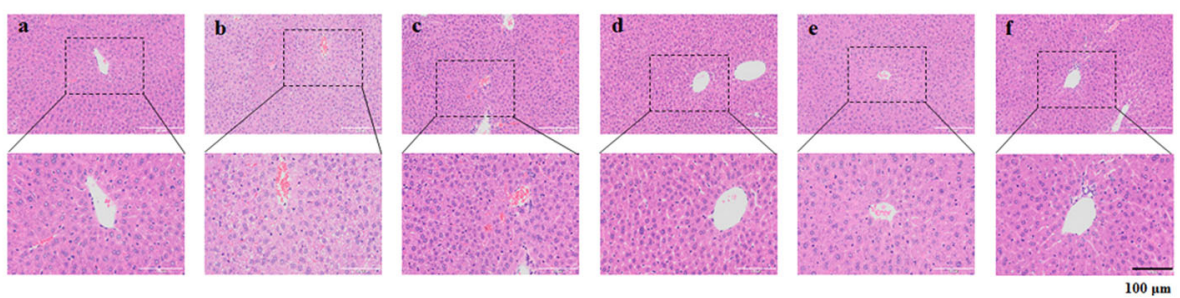

Fig. 7 Quercetin reverses TSN-induced liver injury in mice. C57BL/6 mice were pre-treated with quercetin (Quer; 40, 80 mg/kg) for seven consecutive days and were then administered a single dose of TSN $(10 \mathrm{mg} / \mathrm{kg})$ at $1 \mathrm{~h}$ after quercetin administration on the seventh day. Mice were killed at $24 \mathrm{~h}$ after TSN administration. a Serum ALT/AST activity $(n=8)$. b Serum ALP activity $(n=7-8)$. c Liver GSH content $(n=6)$. d Liver ROS level $(n=6)$. e Liver MDA content $(n=6)$. $\mathbf{f}$ Hepatic mRNA expression of Nrf2 $(n=3)$. $\mathbf{g}$ Hepatic protein expression of Nrf2. The results represent four repeated experiments. $\mathbf{h}$ Quantitative densitometric analysis of Nrf2 $(n=4)$. i Histological evaluation of liver injury. Typical images were chosen from each experimental group (original magnification, $\times 100$, upper images; partial enlarged pictures, $\times 200$, a. control; b. TSN; c. TSN+Quer $40 \mathrm{mg} / \mathrm{kg}$; d. TSN+Quer $80 \mathrm{mg} / \mathrm{kg}$; e. 10\% PC; f. Quer $80 \mathrm{mg} / \mathrm{kg}$ ). The data are expressed as the mean \pm SEM. * $P<$ 0.05 , ${ }^{* *} P<0.01$, ${ }^{* *} P<0.001$ vs. control; ${ }^{*} P<0.05,{ }^{\# \#} P<0.01$, ${ }^{\# \#} P<0.001$ vs. TSN. PG propylene glycol. Scale bar: $100 \mu \mathrm{m}$

occurred and included intrahepatic hemorrhage, hepatic infiltration of immune cells, nuclear pyknosis, and hepatocyte death (Fig. 4d). Next, TSN was shown to increase the liver MDA and ROS contents but decrease the liver GSH content in mice after treatment with TSN for $24 \mathrm{~h}$ (Fig. $4 \mathrm{e}-\mathrm{g}$ ).

TSN reduces hepatic expression of Nrf2 and its downstream GCLC/ GCLM in mice

As shown in Fig. $5 a$ and $b$, TSN reduced hepatic mRNA expression of Nrf2 and its dependent downstream genes, including GCLC and GCLM, after mice were treated with TSN for 6,12 , and $24 \mathrm{~h}$. TSN also decreased hepatic protein expression of Nrf2, GCLC, and GCLM after mice were treated with TSN for 12 and $24 \mathrm{~h}$ (Fig. 5c, d).

Quercetin reverses the decreased Nrf2 activation and the increased cytotoxicity induced by TSN in hepatocytes

The data in Fig. 6 a showed that quercetin $(12.5,25 \mu \mathrm{M})$ reversed the reduced cell viability in L-02 cells induced by TSN $(2 \mu \mathrm{M})$.
Quercetin $(25,50 \mu \mathrm{M})$ reversed the decreased Nrf2 mRNA expression induced by TSN in L-02 hepatocytes (Fig. 6b). The TSN-induced decrease in Nrf2/1 transcriptional activation in hepatocytes was reversed by quercetin (25, $50 \mu \mathrm{M})$ (Fig. 6c). Western blot analysis further showed that quercetin $(25,50 \mu \mathrm{M})$ reversed the reduced cellular expression of Nrf2, GCLC, and GCLM induced by TSN in L-02 hepatocytes (Fig. 6d, e). In addition, quercetin $(25,50 \mu \mathrm{M})$ reversed the decreased mRNA expression of GCLC and GCLM induced by TSN in L-02 hepatocytes (Fig. 6f). Quercetin $(25,50 \mu \mathrm{M})$ reversed the decreased cellular $\mathrm{GCL}$ activity induced by TSN in L-02 hepatocytes (Fig. $6 \mathrm{~g}$ ). Moreover, the TSNinduced decrease in the cellular GSH content was reversed by quercetin $(25 \mu \mathrm{M})$ (Fig. 6h).

Quercetin reverses TSN-induced liver injury in mice

Fig. $7 \mathrm{a}$ and $\mathrm{b}$ shows that quercetin $(40,80 \mathrm{mg} / \mathrm{kg})$ reduced the elevated serum ALT, AST, and ALP activities induced by TSN $(10 \mathrm{mg} / \mathrm{kg})$ in mice. Quercetin $(80 \mathrm{mg} / \mathrm{kg})$ alone exhibited no 


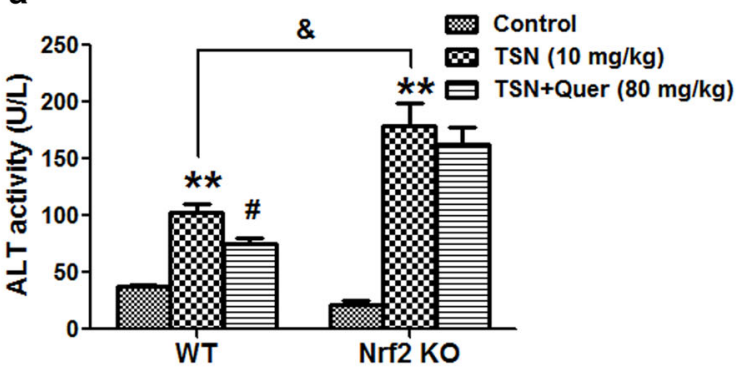

C
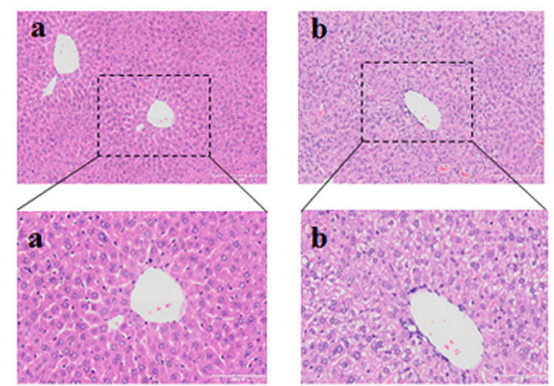

WT b
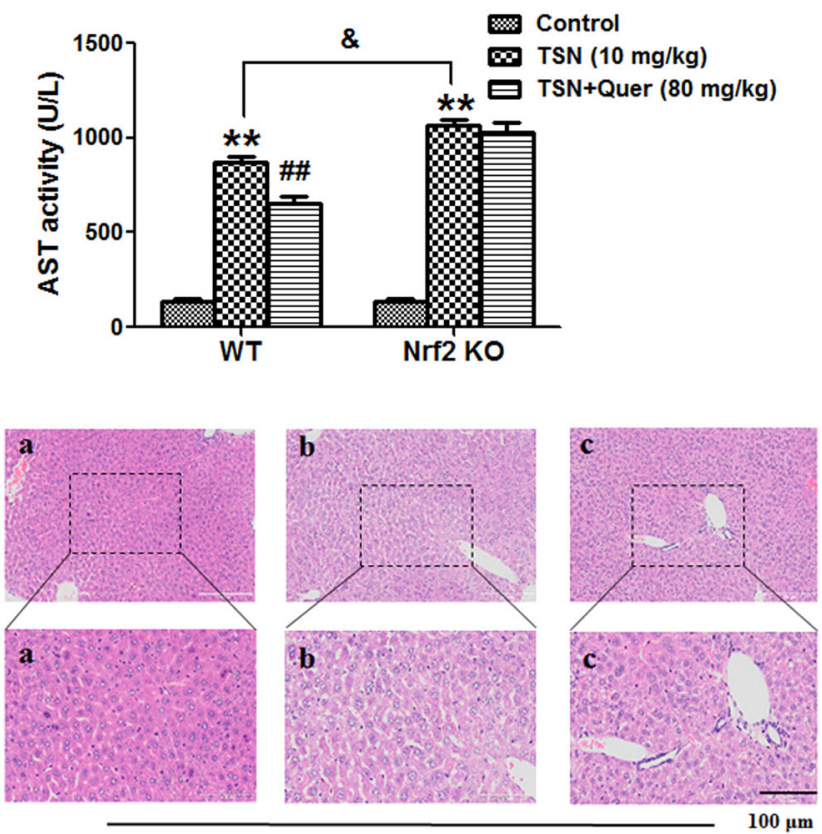

Nrf2 KO

Fig. $8 \mathrm{Nrf2}$ is critical to protect quercetin against TSN-induced liver injury in mice. C57BL/6 wild-type (WT) and Nrf2 knock-out (KO) mice were pre-treated with quercetin (Quer; $80 \mathrm{mg} / \mathrm{kg}$ ) for seven consecutive days and were then administered a single dose of TSN (10 mg/kg) $1 \mathrm{~h}$ after quercetin administration on the seventh day. Mice were killed $24 \mathrm{~h}$ after TSN administration. a Serum ALT activity. b Serum AST activity. c Histological evaluation of liver injury. Typical images were chosen from each experimental group (original magnification, $\times 100$, upper images; partial enlarged pictures, $\times 200$, a. control; b. TSN; c. TSN+Quer). The data are expressed as the mean \pm SEM ( $n=6)$. ${ }^{* *} P<0.01$ vs. control; ${ }^{\#} P<0.05,{ }^{\# \#} P<0.01$ v.s. TSN; ${ }^{\&} P<0.05$ vs. WT mice. Scale bar: $100 \mu \mathrm{m}$

hepatotoxicity in mice. Quercetin $(40,80 \mathrm{mg} / \mathrm{kg}$ ) also reversed the decreased liver GSH content and increased hepatic ROS formation induced by TSN in mice (Fig. 7c, d). Quercetin ( $80 \mathrm{mg} / \mathrm{kg}$ ) reduced the TSN-induced increase in the liver MDA content in mice (Fig. 7e). Subsequently, quercetin $(80 \mathrm{mg} / \mathrm{kg})$ reversed the decreased hepatic mRNA and protein expression levels of Nrf2 induced by TSN in mice (Fig. 7f-h). Finally, liver histological observation also demonstrated the protection of quercetin against TSN-induced liver damage, including reduced intrahepatic hemorrhage and decreased nuclear pyknosis (Fig. 7i).

Nrf2 is critical for the protection of quercetin against TSN-induced liver injury in mice

Next, Nrf2 knock-out mice were used to confirm the critical role of Nrf2 in TSN-induced hepatotoxicity. As shown in Fig. 8a and b, quercetin $(80 \mathrm{mg} / \mathrm{kg})$ significantly reduced the increased serum ALT and AST activities induced by TSN in wild-type mice, but quercetin $(80 \mathrm{mg} / \mathrm{kg})$ had no inhibitory effect on the TSN-induced increase in serum ALT and AST activities in Nrf2 knock-out mice. Moreover, the TSN-induced increase in serum ALT and AST activities was significantly higher in Nrf2 knock-out mice than in wild-type mice (Fig. 8a, b).

Further liver histological evaluation showed that quercetin prevented TSN-induced liver damage in wild-type mice, including reduced hepatocyte death and decreased nuclear pyknosis (Fig. 8c). However, such protection was diminished in Nrf2 knock-out mice.

\section{DISCUSSION}

TSN is the main active compound in Toosendan Fructus and Meliae Cortex and has well-known insecticidal activity [12, 13]. Recently, an increasing number of studies have focused on studying the anti-cancer effect of TSN and its mechanism. These studies showed that the effective anti-cancer dose of TSN in vivo is $<1 \mathrm{mg} / \mathrm{kg}$ and that the effective anti-cancer concentration of TSN in vitro is <500 nM $[7-11,35,36]$. TSN has already been reported to induce hepatotoxicity both in vivo and in vitro $[14,15]$. In this study, TSN was also found to induce hepatotoxicity in mouse (10 mg/kg) and human normal liver L-02 hepatocytes (500 nM TSN results in the reduction of cell viability by $20 \%$ ). Our results and those of previous studies suggest that we should focus more on TSN-induced hepatotoxicity when studying its anti-tumor activity. In addition, this study also alerts people to hepatotoxicity induced by TSN-containing TCMs such as Toosendan Fructus and Meliae Cortex.

The result of ROS formation and amount of MDA indicated that TSN induced liver oxidative injury both in vivo and in vitro. GSH, a well-known antioxidant sulfhydryl (-SH) tripeptide, is important for the maintenance of the cellular redox state and prevention of oxidative injury [37]. TSN was found to decrease the hepatic GSH content in mice and the cellular GSH content in hepatocytes. The GSH biosynthesis inhibitor BSO aggravated the TSN-induced decrease in cell viability and GSH content, but the GSH precursor NAC reversed these phenomena. Those results confirmed the critical protection of GSH against TSN-induced hepatotoxicity.

$\mathrm{GCL}$ is the rate-limiting enzyme for cellular GSH biosynthesis [34]. In this study, TSN was found to decrease GCL enzymatic activity. Moreover, TSN decreased the expression of GCLC and GCLM both in vitro and in vivo, possibly explaining why TSN reduced GCL enzymatic activity. GCLC and GCLM are both reported to be Nrf2-dependent downstream genes [34]. Further results showed that TSN decreased Nrf2 expression, thus leading to reduced transcriptional activation of Nrf2. All of these results imply that TSN decreased the GSH content by reducing $\mathrm{GCL}$ activity via inhibition of Nrf2-mediated GCLC/GCLM expression.

Keap1 is an adapter for Cul3/Rbx1-mediated protein degradation of Nrf2 and acts as an inhibitor protein for Nrf2 by binding to 
Nrf2 [16]. P62 was reported to activate Nrf2 by binding to Keap1, thus leading to the dissociation of Nrf2 and Keap1 [38]. In this study, TSN increased Keap1 expression and decreased p62 expression, which may cause the dissociation of Nrf2/Keap1 and lead to Nrf2 degradation. Further results showed that TSN induced Nrf2 polyubiquitination in hepatocytes and that the proteasome inhibitor MG132 reversed the TSN-induced decrease in Nrf2 expression. These results imply that TSN induces ubiquitin/ proteasome-mediated $\mathrm{Nrf2}$ protein degradation. TSN also decreased Nrf2 mRNA expression both in vivo and in vitro. Thus, TSN decreased Nrf2 expression not only by inhibiting gene expression but also by inducing protein degradation.

Next, whether quercetin can alleviate TSN-induced liver injury by inducing Nrf2 activation was investigated. Quercetin was found to prevent TSN-induced hepatotoxicity both in vitro and in vivo. Quercetin reversed the decreased Nrf2 and GCLC/GCLM expression, GCL activity and GSH content induced by TSN. Those results indicate that quercetin prevents TSN-induced hepatotoxicity via attenuation of liver oxidative injury by enhancing Nrf2-mediated GCLC/GCLM expression and subsequent GSH biosynthesis. Previous studies have already demonstrated that quercetin can prevent various hepatotoxicant-induced liver oxidative injuries by inducing Nrf2 activation [23, 27-29]. This study further confirmed the critical protective role of $\mathrm{Nrf} 2$ involved in this quercetinprovided hepatoprotective effect. Moreover, some studies showed that quercetin exists in Toosendan Fructus [39] and that its content was $4.30-20.48 \mu \mathrm{g} / \mathrm{g}$, which is $\sim 7-10$ times of the content of TSN $(0.6-20.00 \mu \mathrm{g} / \mathrm{g})$ [5]. Thus, quercetin-provided the protection against TSN-induced hepatotoxicity in this study further implies that detoxifying ingredients exist in toxic Toosendan Fructus itself, indicating the rational application of TCMs as a whole medicine. Moreover, numerous studies demonstrated the possible therapeutic value of quercetin for cancer prevention and intervention [40-42], implying that the combination of quercetin with TSN may be a good strategy for cancer prevention.

To further confirm the critical role of Nrf2 in TSN-induced liver injury, Nrf2 knock-out mice were used. TSN-induced liver injury was more serious in Nrf2 knock-out mice than in wild-type mice, and the quercetin-provided protection against TSN-induced hepatotoxicity was diminished in Nrf2 knock-out mice. These results imply that $\mathrm{Nrf2}$ is critical to prevent TSN-induced liver injury.

In summary, this study showed, for the first time, the critical protective role of Nrf2 against TSN-induced hepatotoxicity. TSN decreased the GSH content by reducing Nrf2-mediated GCLC/ GCLM expression by inducing $\mathrm{Nrf2}$ protein degradation and decreasing Nrf2 mRNA expression; and quercetin alleviated TSNinduced hepatotoxicity by activating the Nrf2/GCL/GSH antioxidant signaling pathway. Inducing Nrf2 activation may be an effective approach to prevent liver injury caused by TSN and TCMs containing TSN.

\section{ACKNOWLEDGEMENTS}

This work was financially supported by the State Major Science and Technology Special Projects during the 12th Five-year Plan (2015ZX09501004-002-002) and the National Natural Science Foundation of China $(81322053,81573679)$

\section{AUTHOR CONTRIBUTIONS}

YJ and L-IJ conceived and designed the experiments; YJ, Z-IH, LL, and YY performed the experiments; $\mathrm{YJ}$ and $\mathrm{Z}-\mathrm{IH}$ analyzed the data; C-hW and Z-tW contributed new reagents; L-IJ wrote the manuscript.

\section{ADDITIONAL INFORMATION}

Supplementary information is available for this paper at https://doi.org/10.1038/ s41401-018-0024-8.
Competing interests: The authors declare no competing interests.

Publisher's note: Springer Nature remains neutral with regard to jurisdictional claims in published maps and institutional affiliations.

\section{REFERENCES}

1. Ma X, Peng JH, Hu YY. Chinese herbal medicine-induced liver injury. J Clin Transl Hepatol. 2014;2:170-5.

2. Bunchomtavakul C, Reddy K. Review article: herbal and dietary supplement hepatotoxicity. Aliment Pharmacol Ther. 2013;37:3-17.

3. Teo DC, Ng PS, Tan SH, Lim AT, Toh DS, Chan SY, et al. Drug-induced liver injury associated with complementary and alternative medicine: a review of adverse event reports in an Asian community from 2009 to 2014. BMC Complement Altern Med. 2016;16:192.

4. Zhang $P$, Ye YG, Yang XZ, Jiao YT. Systematic review on Chinese herbal medicine induced liver injury. Evid Based Complement Altern Med. 2016;2016:3560812.

5. Chinese Pharmacopoeia Commission. Pharmacopeia of the people's republic of China (2015) version. Beijing: The Medicine Science and Technology Press of China; 2015. p. 203.

6. Shi YL, Li MF. Biological effects of toosendanin, a triterpenoid extracted from Chinese traditional medicine. Prog Neurobiol. 2007;82:1-10.

7. Zhang T, Li J, Yin F, Lin B, Wang Z, Xu J, et al. Toosendanin demonstrates promising anti-tumor efficacy in osteosarcoma by targeting STAT3. Oncogene. 2017;36:6627-39.

8. Li X, You M, Liu YJ, Ma L, Jin PP, Zhou R, et al. Reversal of the apoptotic resistance of non-small-cell lung carcinoma towards TRAIL by natural product Toosendanin. Sci Rep. 2017;7:42748.

9. Cao L, Qu D, Wang H, Zhang S, Jia C, Shi Z, et al. Toosendanin exerts an anticancer effect in glioblastoma by inducing estrogen receptor $\beta$ - and $p 53-$ mediated apoptosis. Int J Mol Sci. 2016;17:E1928.

10. Wang G, Feng CC, Chu SJ, Zhang R, Lu YM, Zhu JS, et al. Toosendanin inhibits growth and induces apoptosis in colorectal cancer cells through suppression of AKT/GSK-3 $\beta / \beta$-catenin pathway. Int J Oncol. 2015;47:1767-74.

11. He Y, Wang J, Liu X, Zhang L, Yi G, Li C, et al. Toosendanin inhibits hepatocellular carcinoma cells by inducing mitochondria-dependent apoptosis. Planta Med. 2010;76:1447-53.

12. Xu H, Zhang JL. Natural products-based insecticidal agents 9. Design, semisynthesis and insecticidal activity of 28-acyloxy derivatives of toosendanin against Mythimna separata Walker in vivo. Bioorg Med Chem Lett. 2011;21:1974-7.

13. Zhang J, Qu H, Yu X, Zhi X, Chen H, Xu H. Combinatorial synthesis of a series of alkyl/alkenylacyloxy derivatives at the $\mathrm{C}-28$ position of toosendanin as insecticidal agents. Comb Chem High Throughput Screen. 2013;16:394-9.

14. Zhang YH, Qi XM, Gong LK, Li Y, Liu LL, Xue X, et al. Roles of reactive oxygen species and MAP kinases in the primary rat hepatocytes death induced by toosendanin. Toxicology. 2008;249:62-8.

15. Lu X, Ji C, Tong W, Lian X, Wu Y, Fan X, et al. Integrated analysis of microRNA and mRNA expression profiles highlights the complex and dynamic behavior of toosendanin-induced liver injury in mice. Sci Rep. 2016;6:34225.

16. Kaspar JW, Niture SK, Jaiswal AK. Nrf2:INrf2 (Keap1) signaling in oxidative stress. Free Radic Biol Med. 2009;47:1304-9.

17. Klaassen $C D$, Reisman SA. Nrf2 the rescue: effects of the antioxidative/electrophilic response in the liver. Toxicol Appl Pharmacol. 2010;244:57-65.

18. Bataille AM, Manautou JE. Nrf2: A potential target for new therapeutics in liver disease. Clin Pharmacol Ther. 2012;92:340-8.

19. Jadeja RN, Upadhyay KK, Devkar RV, Khurana S. Naturally occurring Nrf2 activators: potential in treatment of liver injury. Oxid Med Cell Longev. 2016;2016:3453926.

20. Boots AW, Haenan GRMM, Bast A. Health effects of quercetin: from antioxidant to nutraceutical. Eur J Pharmacol. 2008;585:325-37.

21. Ji LL, Ma YB, Wang ZY, Cai ZX, Pang C, Wang ZT. Quercetin prevents pyrrolizidine alkaloid clivorine-induced liver injury in mice by elevating body defense capacity. PLoS ONE. 2014;9:e98970.

22. Liu CM, Zheng GH, Ming QL, Sun JM, Cheng C. Protective effect of quercetin on lead-induced oxidative stress and endoplasmic reticulum stress in rat liver via the IRE1/JNK and PI3K/Akt pathway. Free Radic Res. 2013;47:192-201.

23. Liu CM, Ma JQ, Xie WR, Liu SS, Feng ZJ, Zheng GH, et al. Quercetin protects mouse liver against nickel-induced DNA methylation and inflammation associated with the Nrf2/HO-1 and p38/STAT1/NF-KB pathway. Food Chem Toxicol. 2015;82:19-26. 
24. Peng Z, Gong X, Yang Y, Huang L, Zhang Q, Zhang P, et al. Hepatoprotective effect of quercetin against LPS/d-GalN induced acute liver injury in mice by inhibiting the IKK/NF-KB and MAPK signal pathways. Int Immunopharmacol. 2017;52:281-9.

25. Wei CB, Tao K, Jiang R, Zhou LD, Zhang QH, Yuan CS. Quercetin protects mouse liver against triptolide-induced hepatic injury by restoring Th17/Treg balance through Tim-3 and TLR4-MyD88-NF-KB pathway. Int Immunopharmacol. 2017;53:73-82.

26. Kemelo MK, Pierzynova A, Kutinova Canova N, Kucera T, Farqhali H. The involvement of sirtuin 1 and heme oxygenase 1 in the hepatoprotective effects of quercetin against carbon tetrachloride-induced sub-chronic liver toxicity in rats. Chem Biol Interact. 2017;269:1-8.

27. Ji LL, Sheng YC, Zheng ZY, Shi L, Wang ZT. The involvement of p62-Keap1-Nrf2 antioxidative signaling pathway and JNK in the protection of natural flavonoid quercetin against hepatotoxicity. Free Radic Biol Med. 2015;85:12-23.

28. Domitrovic R, Jakovac H, Vasiljev Marchesi V, Vladimir-knezevic S, Cvijanovia O, Tadic $Z$, et al. Differential hepatoprotective mechanisms of rutin and quercetin in CCI(4)-intoxicated BALB/CN mice. Acta Pharmacol Sin. 2012;33:1260-70.

29. Wen CJ, Chen MJ, Yeh CT, Yen GC. Hepatoprotection of quercetin against oxidative stress by induction of metallothionein expression through activating MAPK and PI3K pathways and enhancing Nrf2 DNA-binding activity. N Biotechnol. 2011;28:767-77.

30. Pang C, Zheng ZY, Shi L, Sheng YC, Wei H, Wang ZT, et al. Caffeic acid prevents acetaminophen-induced liver injury by activating the Keap1-Nrf2 antioxidative defense system. Free Radic Biol Med. 2016;91:236-46.

31. Liang $Q N$, Sheng $Y C$, Jiang $P$, Ji LL, Xia YY, Min $Y$, et al. The gender-dependent difference of liver GSH antioxidant system in mice and its influence on isolineinduced liver injury. Toxicology. 2011;280:61-9.
32. Griffith OW. Mechanism of action, metabolism and toxicity of buthionine sulfoximine and its higher homologs, potent inhibitors of glutathione synthesis. Biol Chem. 1982;257:13704-12.

33. Kelly GS. Clinical applications of N-acetylcysteine. Altern Med Rev. 1998;3:114-27.

34. Lu SC. Glutathione synthesis. Biochim Biophys Acta. 2013;1830:3143-53.

35. Ju J, Qi Z, Cai X, Cao P, Huang Y, Wang S, et al. The apoptotic effects of toosendanin are partially mediated by activation of deoxycytidine kinase in HL-60 cells. PLoS ONE. 2012;7:e52536.

36. Zhang B, Wang ZF, Tang MZ, Shi YL. Growth inhibition and apoptosis-induced effect on human cancer cells of toosendanin, a triterpenoid derivative from Chinese traditional medicine. Invest New Drugs. 2005;23:547-53.

37. DeLeve LD, Kaplowitz N. Glutathione metabolism and its role in hepatotoxicity. Pharmacol Ther. 1991;52:287-305.

38. Komatsu M, Kurokawa $H$, Waguri S, Taguchi K, Kobayashi A, Ichimura $Y$, et al. The selective autophagy substrate p62 activates the stress responsive transcription factor Nrf2 through inactivation of Keap1. Nat Cell Biol. 2010;12:213-23.

39. Zhou N, Yang Q, Yang M, Zhang DQ, Jiang B, Li XZ. Simultaneous determination of rutin, isoquercitrin and quercetin contents in Fructus Toosendan by HPLC. Chin J Pharm Anal. 2013;2:225-9.

40. Tewari D, Nabavi SF, Nabavi SM, Sureda A, Farooqi AA, Atanasov AG, et al. Targeting activator protein 1 signaling pathway by bioactive natural agents: possible therapeutic strategy for cancer prevention and intervention. Pharmacol Res. 2017;128:366-75.

41. Kashyap D, Mittal S, Sak K, Sinqhal P, Tuli HS. Molecular mechanisms of action of quercetin in cancer: recent advances. Tumour Biol. 2016;37:12927-39.

42. Khan F, Niaz K, Maqbool F, Ismail Hassan F, Abdollahi M, Nagulapalli Venkata KC, et al. Molecular targets underlying the anticancer effects of quercetin: an update. Nutrients. 2016;8:529. 